\title{
Performance evaluation and prediction for a pilot two-stage on-site constructed wetland system employing dewatered alum sludge as main substrate
}

\author{
A.O. Babatunde', Y.Q. Zhao*, R.J. Doyle, S.M. Rackard, J.L.G. Kumar and Y.S. Hu
}

Centre for Water Resources Research, School of Architecture, Landscape and Civil Engineering, University College Dublin, Belfield, Dublin 4, Ireland

\author{
*Corresponding author: Yaqian Zhao \\ Telephone, +353-1-7163215; fax.+353-1-7163297; e-mail, yaqian.zhao@ucd.ie

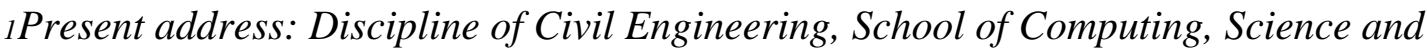 \\ Engineering, University of Salford, Salford, M5 4WT, Greater Manchester, U.K.
}

\begin{abstract}
Dewatered alum sludge, a widely generated by-product of drinking water treatment plants using aluminium salts as coagulants was used as main substrate in a pilot on-site constructed wetland system treating agricultural wastewater for 11 months. Treatment performance was evaluated and spreadsheet analysis was used to establish correlations between water quality variables. Results showed that removal rates (in $\mathrm{g} / \mathrm{m}^{2}$.d) of $4.6-249.2$ for 5 day biochemical oxygen demand $\left(\mathrm{BOD}_{5}\right)$, 35.6-502.0 for chemical oxygen demand (COD), 2.5-14.3 for total phosphorus (TP) and 2.7-14.6 for phosphate $\left(\mathrm{PO}_{4}-\mathrm{P}\right)$ were achieved. Multiple regression analysis showed that effluent $\mathrm{BOD}_{5}$ and $\mathrm{COD}$ can be predicted to a reasonable accuracy $\left(\mathrm{R}^{2}=0.665\right.$ and 0.588 , respectively) by using input variables which can be easily monitored in real time as sole predictor variables. This could provide a rapid and cheap alternative to such laborious and time consuming analyses and also serve as management tools for day-to-day process control.
\end{abstract}

Keywords: Alum sludge; constructed wetland; phosphorus; water treatment residual; multiple regression analysis 


\section{Introduction}

Constructed wetland $(\mathrm{CW})$ systems are becoming increasingly popular in response to increasing environmental issues and growing importance of natural and sustainable wastewater treatment systems. They are regarded as cost-effective and eco-friendly treatment systems with low maintenance and comparatively less energy consumption (Tomenko et al., 2007). They are also fast becoming the system of choice for wastewater treatment especially in rural or isolated areas where conventional systems are not as feasible because of cost effectiveness. It is well known that wastewater treatment in $\mathrm{CW}$ systems involve complex physical, chemical and biological processes.

Consequently, CW systems are often seen as complex "black box" systems and the processes within them are difficult to model due to the complexity of the relationships between most water quality variables (Gernaey et al., 2004; Lee and Scholz, 2006). On the other hand, the appropriate design, operation and evaluation of CW systems are crucial as well as contingent on a good understanding of the internal treatment processes and mechanisms. Regression analysis has been found to be useful for simplified description and analysis of CW systems performance as they provide a means of understanding their treatment process/mechanism (Tomenko et al., 2007; Murray-Gulde et al., 2008; Tang et al., 2009). Although, there are many more approaches with stronger capabilities that could be used to model CW systems performance such as artificial neural networks and multi-component reactive transport module (CW2D) (Langergraber, 2008; Akratos et al., 2009), the use of these complex approaches has been limited and yet to be proven.

The CW system described in the present study employs dewatered alum sludge as the main substrate in line with recent trends aimed at using natural and by-products as substrates in CW systems, e.g. limestone pellets (Tao and Wang, 2008) and filtralite (Albuquerque et al., 2009). Alum sludge is a by-product of drinking water treatment plants utilizing aluminum salts as coagulants. It is the most widely generated drinking water treatment residual and it is mostly landfilled, being perceived as a by-product of limited reuse value (Babatunde and Zhao, 2007). Therefore, the beneficial reuse of alum sludge in CW systems, hitherto considered as a waste by-product for wastewater treatment, may present an innovative approach of using waste for wastewater treatment. Extensive laboratory scale studies on the 
novel reuse of alum sludge in CW systems have been conducted in the authors research group (Zhao et al., 2009). Trials of several CW systems using the alum sludge as substrate are currently being conducted as pilot field-scale demonstrations to treat wastewater emanating from an animal research farm (Zhao et al., 2010). It is expected that these novel CW systems will offer a sustainable and cost-effective solution to the treatment of agricultural wastewaters, which is a wide-spread challenge particularly across the European Union. Until now, the prevalent practice on many farms is to store dirty water and spray it onto fields during the dry season and this has been found to cause degradation of surface and groundwaters (Wood et al., 2007). However, before the application of the novel CW systems on full scale, it is imperative to analyse their performance as a pilot field-scale model first. Therefore, this study presents performance analysis of a two-stage on-site CW system utilizing alum sludge as main substrate and explores the newly developed model for predicting final effluent concentrations. The key issues addressed are analysis of the CW system performance, identification of correlations among the water quality variables and the development of statistical models for predicting final effluent concentrations.

\section{Materials and methods}

\subsection{Design and operation of the system}

The pilot field-scale CW system was constructed on an animal research farm in Newcastle, Co. Dublin, Ireland to treat wastewater (after settlement) emanating from the farm. The system consists of two stages operated with a hydraulic loading rate of $0.56 \mathrm{~m}^{3} / \mathrm{m}^{2} . \mathrm{d}$ and a hydraulic retention time of 4 hours in each stage. The system is configured (from the top) with $20 \mathrm{~mm}$ gravel as distribution layer in the $0-10 \mathrm{~cm}$ depth range and this is followed 10$75 \mathrm{~cm}$ of dewatered alum sludge cakes as the main substrate layer and then $75-85 \mathrm{~cm}$ of $10 \mathrm{~mm}$ gravel as the support/drainage layer. The stages of the system, each with a total surface area of $1.17 \mathrm{~m}^{2}$, were linked together using pipes connected to a submersible pump placed in each stage. The dewatered alum sludge cakes used were collected fresh from the industrial filter press of a drinking water treatment plant in Southwest Dublin, Ireland where aluminium sulphate is used as coagulant. The size/length (mean $\pm \mathrm{SD})$ of the alum sludge cakes used was $7.25 \pm 1.48 \mathrm{~cm}$. The characteristics of the alum sludge have been well investigated and reported elsewhere (Babatunde et al., 2009). Common reeds, Phragmites australis, were 
planted on top of each stage. The system was operated as a subsurface flow system using a tidal flow operation strategy, which allows the matrices of the system to be filled with wastewater, and then to be completely drained to enhance the aeration (Green et al., 1998). In this regards, the system was not designed to rely solely on Phragmites australis for oxygen transfer into the system especially during the start up period. Wastewater from the farm activities was firstly collected from the holding tank on the farm and pumped into a $10 \mathrm{~m}^{3}$ capacity tank. Appropriate dilution was then carried out to achieve desired concentration.

\subsection{Data capture and analysis and model development}

Water quality data were obtained by monitoring pollutant concentration in the influent and effluent samples of the system over a period of 11 months. Samples were analysed for COD (both total and soluble COD, (sCOD)), BOD5 (Lovibond OxiDirect apparatus, Lennox, UK), TP (Ascorbic method, Clesceri et al., 1998), PO4-P, total nitrogen (TN) (Persulfate method, Clesceri et al., 1998), ammonium nitrogen $\left(\mathrm{NH}_{4}-\mathrm{N}\right)$, nitrate nitrogen $\left(\mathrm{NO}_{3}-\mathrm{N}\right)$, nitrate nitrogen $\left(\mathrm{NO}_{2}-\mathrm{N}\right)$, suspended solids (SS) and Turbidity (Hach turbidity meter $2100 \mathrm{~N}$ IS). Except where indicated, all the water quality parameters were analysed using a Hach DR/2400 spectrophotometer according to its standard operating procedures. From the water quality data, removal efficiencies and pollutant loading and removal rates were determined. Pollutant loading rate $\left(\mathrm{g} / \mathrm{m}^{2} . \mathrm{d}\right)$ was calculated by multiplying the hydraulic loading rate $\left(\mathrm{m}^{3} / \mathrm{m}^{2} . \mathrm{d}\right)$ by the influent pollutant concentration $(\mathrm{mg} / \mathrm{l})$ while pollutant removal rate $\left(\mathrm{g} / \mathrm{m}^{2} . \mathrm{d}\right)$ was defined as hydraulic loading rate multiplied by the difference in concentration between the influent and effluent. However, more emphasis was paid to the loading and removal rates. Metrological data was obtained from Irish Metrological service (www.met.ie) while real time measurements of oxidation-reduction potential (ORP), temperature and $\mathrm{pH}$ were obtained from an YSI multi-parameter probe inserted in the influent tank and in each stage of the CWs.

Correlations were sought between the different water quality variables and regression analysis and analysis of variance (ANOVA) were performed to determine if significant relationships existed between influent and effluent concentrations. By investigating correlations between the different variables, a deeper understanding of the relationship between the variables was obtained and this was used to develop models for the prediction of 
final effluent concentrations using multiple regression analyses (MRA). The models were tested for goodness of fit by using graphical analysis, the Student's $t$ test and the F test. The $\mathrm{p}$ values were then considered for each model in order to determine which parameters were significant in forecasting the dependant variables. The MRA was particularly conducted to test the relationship between each of $\mathrm{BOD}$, $\mathrm{COD}, \mathrm{sCOD}$ and $\mathrm{TP}$ and other variables. The reason for these four variables being chosen as dependant variables are because firstly, BOD5 analysis is crucial as it is widely applied to give a general indication of water quality status. Thus, it would be useful to be able to predict BOD5 using other parameters that can be obtained in real time. Secondly, in the case of COD and SCOD, although they are relatively quick to analyse, they are very expensive and this can lead to substantial costs over a long period of testing. Finally TP was chosen because phosphorus (P) is a key factor in causing eutrophication and the analysis can also be time consuming.

After the models have been constructed, they were graphically analysed for goodness of fit by plotting the actual against the predicted results. The adjusted $\mathrm{R}^{2}$ values were taken into account and the result of the $\mathrm{F}$ test was then observed for each model. These values were used in conjunction with the $95 \%$ confidence interval set during the regression. The significant $\mathrm{F}$ values had to be below 0.05 for there to be any significant statistical relationship present. The $\mathrm{p}$ values for each independent variable were also analysed to see how significant they were in predicting the dependant variable. This was done by setting thresholds of $0.05,0.01$ and 0.001. If $\mathrm{p}<0.05$, a parameter was deemed to be significant as the probability that the parameter influences the dependant variable was $95 \%$. This variable then received an asterisk

* according to the "Three Star" scale. If $\mathrm{p}<0.01$ it was then said to be highly significant and was denoted by two asterisks $* *$ and if $\mathrm{p}<0.001$ it received three asterisks $* * *$ and was described as extremely significant.

\section{Results and discussion}

\subsection{Treatment performance}

The characteristics of the source wastewater varied greatly over time in concert with seasonal changes and farming operations. With regards to the characteristics of the influent wastewater to the $\mathrm{CW}$ system, the range of pollutant concentration were BOD5 (31- $968 \mathrm{mg} / \mathrm{L}$ ), COD 
(124-1634 mg/L), PO4-P (2.8-60 mg-P/L), TN (16-273 mg-N/L) and SS (25-633 mg/L).

Figure 1 shows the trend of $\mathrm{pH}$, temperature and ORP in the influent and effluent wastewater. $\mathrm{pH}$ between the influent and effluent varied very little with a standard deviation of ca. 0.1 for both the influent and effluent $\mathrm{pH}$ values. However, the influent $\mathrm{pH}$ is mostly higher than that for the effluent. It is also noted that during wastewater passage through the system, $\mathrm{pH}$ was consistently reduced by between 0.2 and 0.7 units giving relatively stable mean effluent $\mathrm{pH}$ values between 6.6-6.9. ORP fluctuated greatly with negative values being more prevalent. However, there was a difference of approximately $200 \mathrm{mV}$ between the influent and effluent OPR values, with the influent ORP being more negative. This implies that the effluent can be said to be more oxidised but the conditions are still reducing due to the organic load. Figure 1 also shows that that there is little difference in temperature between the influent and the effluent exiting the system. The $P$. australis planted in the $\mathrm{CW}$ grew very well in the alum sludge medium which confirms the previous findings of Babatunde et al. (2009) that alum sludge is not a harmful growth medium for wetland plants.

\section{[INSERT FIG 1 HERE]}

Analysis of removal efficiencies (data not shown) indicate that a range of removal efficiencies of (18-88)\% for BOD5, (14-84)\% for COD, (52-100)\% for TP, (54-100)\% for PO4-P, (15-76)\% for TN, (22-92)\% for NH4-N, and (16-93)\% for SS was achieved. The CW system demonstrated a gradual increase in treatment efficiency and except for periods when there were operational disruptions, most of the lower removal efficiencies were recorded during the start up. However, both TP and $\mathrm{PO}_{4}-\mathrm{P}$ removal were relatively high and consistent throughout the monitoring period. In relative terms, these removal efficiencies can be considered as excellent and showing good promise. An interesting feature of the performance is that it showed a distinctive superior performance regarding phosphorus $(\mathrm{P})$ removal and this can be attributed to the P removing ability of the alum sludge. It is well known that it is often a challenge to achieve concurrent high removal efficiencies for $\mathrm{P}$ and organic matter in $\mathrm{CW}$ systems. CW systems are usually efficient in organics (BOD5, COD) reduction, but the corresponding removal efficiencies for nitrogen $(\mathrm{N})$ and $\mathrm{P}$ are often low (Vymazal, 2007; Park, 2009). This study has demonstrated that by using alum sludge as substrate, high $P$ removal efficiency can be achieved alongside high removal efficiency for organics. Table 1 shows loading and removal rates for respective pollutants in the CWs. Generally, the observed removal rates closely followed the loading rates with high removal rates obtained at 
high loading rates. The system achieved pollutant removal rates ranging from 4.6-249.2 $\mathrm{g} / \mathrm{m}^{2}$.d for BOD5, 35.6-502.0 $\mathrm{g} / \mathrm{m}^{2} . \mathrm{d}$ for COD and 2.7-14.6 $\mathrm{g} / \mathrm{m}^{2} . \mathrm{d}$ for PO4-P. Compared to removal rates found in literature, it can be said that the CWs has a considerable high capacity to degrade pollutants and it may be used as an effective method to reduce pollution load from farms. For instance, removal rates found in literature range from 17.8-20.0 g/ $\mathrm{m}^{2} . \mathrm{d}$ for COD (Kantawanichkul et al., 2009; Konnerup et al., 2009) and 0.23-0.9 g/ $/ \mathrm{m}^{2}$.d for PO4-P (Lin et al., 2002). The comparatively higher removal rates achieved for organics removal in the CW system can be attributed to the enhanced oxygen transfer capacity of the tidal flow operation strategy (Green et al., 1998), which leads to higher degradation rates for the organics. Thus, despite the high organic loading rates, high removal rates were still achieved. The high removal rates achieved for $\mathrm{PO}_{4} \mathrm{P}$ can also be adduced to the $\mathrm{P}$ removing ability of the alum sludge through the ligand exchange mechanism that has been demonstrated in our previous study (Yang et al., 2006).

\section{[INSERT TABLE 1 HERE]}

Nitrogen processing in the CW system was high with removal rates of $1.3-52.7 \mathrm{~g} / \mathrm{m}^{2} . \mathrm{d}$ for TN and 6.1-61.3 $\mathrm{g} / \mathrm{m}^{2} . \mathrm{d}$ for $\mathrm{NH}_{4}-\mathrm{N}$ being achieved. This compares well and above values of 0.5$2.7 \mathrm{~g} / \mathrm{m}^{2} . \mathrm{d}$ obtained in literature (Vymazal, 2007; Tao and Wang, 2008; Albuquerque et al., 2009; Langergraber et al., 2009). However, although nitrogen processing was high in the CWs, it was not complete. Nitrogen removal in CW systems occurs through adsorption, assimilation into microbial and plant biomass, ammonia volatilization and coupled nitrification/denitrification (Vymazal, 2007). Ammonia volatilization in the CW system was probably very low as ammonia losses through volatilization are insignificant for $\mathrm{pH}<7.5$ and very often, losses are not serious if $\mathrm{pH}<8.0$ (Vymazal, 2007). Furthermore, although plant uptake was not quantified, it could be considered to be of low importance in light of the loadings, and this has been the position in other studies Kantawanichkul et al. (2009); although it is often debated. It can be suggested that the main removal process for $\mathrm{N}$ was probably the denitrification, as the nitrification process, which is a prerequisite for denitrification occurs particularly in the first stage of the CW system as evidenced by increased levels of $\mathrm{NO}_{2}-\mathrm{N}$ and $\mathrm{NO}_{3}-\mathrm{N}$ in effluent from first stage (data not shown). However, denitrification was low leading to potential nitrate accumulation in the CW system. While it is generally acknowledged that nitrate-nitrogen removal is very low in vertical sub-surface flow CW system with an increase in nitrate-nitrogen concentration of outflow commonly 
observed (Vymazal, 2007), it is believed that in the present study, optimization of effluent recirculation from second to the first stage can be used to address this.

\subsection{Correlations and regression analysis}

\subsubsection{Correlation analysis}

Table 2 presents results of the correlation analysis. A weak correlation of 0.5871 was obtained between BOD5 and COD effluent concentrations while no relationship $\left(\mathrm{R}^{2}=0.0612\right)$ was obtained between BOD5 and SCOD effluent concentrations. This indicates that while BOD5 removal is positively correlated with COD removal, there are organics in the effluent which are not amenable to microbial degradation. Virtually no correlation was found between concentrations of $\mathrm{PO}_{4}-\mathrm{P}$ and $\mathrm{BOD}_{5}$ in the effluent as well, indicating that their removal processes are independent of each other. BOD5 is removed in the system through various processes including microbial assimilation, filtration and sedimentation, while $\mathrm{PO}_{4} \mathrm{P}$ is removed mainly by adsorption onto the alum sludge. The relationship between the BOD5 and SS effluents concentrations implies that less than half of the variance is described by the correlation; however, compared to SS, effluent turbidity had a slightly greater effect on the effluent BODs concentration. Also, it can be observed that effluent concentrations of TN and BODs have an extremely weak linear relationship.

\section{[INSERT TABLE 2 HERE]}

Although TN and $\mathrm{NH}_{4}-\mathrm{N}$ effluent concentrations were well correlated $\left(\mathrm{R}^{2}=0.8695\right)$, the correlation between effluent concentration of $\mathrm{NH}_{4}-\mathrm{N}$ and influent concentration of TN was less significant $\left(\mathrm{R}^{2}=0.6582\right)$. This further lends credence to the fact that the main $\mathrm{N}$ removal pathway in the CW system under study is nitrification. The $\mathrm{R}^{2}$ value of 0.7314 for the correlation between effluent Tur and effluent COD shows that this is a positive relation. The correlation of sCOD effluent concentrations with SS effluent concentrations also indicates a strong relationship $\left(\mathrm{R}^{2}=0.6528\right)$ and this also suggest the possibility of a significant relationship between particulate COD and SS. Furthermore, a significant relationship was revealed between effluent concentrations of Tur and SS $\left(R^{2}=0.9091\right)$. However, even though SS correlates well with turbidity in the final effluent, it was observed that the influent turbidity had a greater effect on effluent COD concentrations than it made on BOD5, 
suggesting the presence of non-biodegradable solids as previously indicated. The effluent TP concentrations did not show any relationship with either the influent concentration of SS or turbidity suggesting that the removal of TP is more influenced by the removal of $\mathrm{PO}_{4}-\mathrm{P}$ through adsorption.

\subsubsection{Predictive models}

Table 3 and Figure 2 depict predictive models constructed for predicting final effluent concentrations for $\mathrm{BOD} 5, \mathrm{COD}, \mathrm{sCOD}$ and $\mathrm{TP}$ and predicted values against measured ones are plotted.

\subsubsection{Prediction of final effluent concentrations for biochemical oxygen demand}

For predicting final effluent BOD5 concentrations, 6 models (M1-M6) were constructed using different combinations of predictor variables (see Table 3 and Figure 2a). M1 gave an adjusted $R^{2}$ value 0.765 and the value of significant $F$ was less than 0.001 , which is less than the threshold of 0.05 set during the regression and therefore, the null hypothesis (as explained in section 2.2) can be rejected. Analysis of the $\mathrm{p}$ values for the predictor variables indicates that there is significant relationship between turbidity and the effluent BOD5 concentration. The other predictor variables did not show any significant relationship to effluent BOD5 concentration. M2 gave adjusted $\mathrm{R}^{2}$ value of 0.749 , which also indicates a strong model.

\section{[INSERT TABLE 3 AND FIG 2 HERE]}

Furthermore, it can be seen that there is a highly significant association between the variables as the significant $\mathrm{F}$ value is found to be $1.60 \times 10^{-6}$ and therefore the null hypothesis (as explained in section 2.2) can be rejected. When the $\mathrm{p}$ value is taken into account, turbidity proved again to be very closely related to the $\mathrm{BOD}_{5}$ concentration in the effluent as its value of 0.002 classifies it as highly significant. M3 gave a $R^{2}$ value of 0.763 . The $F$ value was found to be $9.18 \times 10^{-7}$ and therefore, the null hypothesis (as explained in section 2.2) is rejected. The SS concentration of the influent received a $\mathrm{p}$ value of 0.035 , which categorises it as significant, while the turbidity of the influent wastewater is regarded as highly significant due to its $\mathrm{p}$ value of 0.008 . 
The influent $\mathrm{PO}_{4}-\mathrm{P}$ concentration was introduced as a predictor variable in the fourth model (M4) along with influent SS and turbidity concentrations. This gave a $\mathrm{R}^{2}$ value of 0.727 and the significant $\mathrm{F}$ value was found to be $3.44 \times 10^{-6}$ which means that the null hypothesis can be rejected at a $99.9 \%$ confidence level. This is more than acceptable as we stated during the regression that the confidence level would have to be at least $95 \%$, therefore the null hypothesis is rejected and there is a definite significant statistical association shown by the model. The $\mathrm{p}$ values for each predictor variable were analysed and it was found that the $\mathrm{p}$ values for $\mathrm{PO}_{4}-\mathrm{P}$ and $\mathrm{SS}$ were over the threshold value of 0.05 and so the effluent $\mathrm{BOD}_{5}$ cannot be said to be dependent on either of these factors. However, the value for turbidity was shown to be extremely significant as its value was calculated to be 0.001 . The adjusted $\mathrm{R}^{2}$ for M5 was 0.612 and this shows a slight decrease from the previous regressions. Analysis of the $\mathrm{p}$ values of the predictor variables indicate that the influent wastewater temperature is highly significant in predicting the final effluent $\mathrm{BOD}_{5}$. M6 was constructed using data obtained in real time only. The predictor variables used were the influent data for $\mathrm{pH}$, ORP and temperature. This proved to create a reasonably strong model, with an adjusted $\mathrm{R}^{2}$ value of 0.665 . The $F$ test provided a significant $F$ value of 0.00 and therefore, the null hypothesis is rejected and the model has a significant statistical relationship. However, the $\mathrm{p}$ values for all the predictor variables were above the threshold value of 0.05 . Although this is below the confidence level set during regression it is interesting to note that it preformed quite well. Perhaps, it can be suggested that with more data available from longer-term evaluation, the model could probably have been evaluated much longer and possibly perform better. If that is the case, then one is inclined to believe that $\mathrm{BOD}_{5}$ concentration can be evaluated from online measurement of other parameters which are easy and quick to obtain. Plots of actual vs. predicted values for the final effluent BOD5 concentration for models M1, M2 and M3 are presented in Figure 2a and generally, the plots show a good fit between the actual and predicted values.

\subsubsection{Prediction of final effluent concentrations for chemical oxygen demand}

For COD predictions, four models (M2, M3, M4 and M6) were considered to give suitable fitting with the actual observations (see Table 3 and Figure 2b). M2 was constructed using influent concentrations of turbidity, TP and SCOD as predictor variables and it gave an adjusted $\mathrm{R}^{2}$ value of 0.615 . The $\mathrm{F}$ test shows a significant $\mathrm{F}$ value of $4.82 \times 10^{-6}$ which 
indicates that there is a definite statistical significance observed and the null hypothesis is rejected. When the $\mathrm{p}$ values of the predictor variables are taken into account, it is observed that only sCOD is above the threshold to accept the null hypothesis which implies that it does not display a relationship with the effluent COD concentration. This could suggest the presence of background refractory organics in the influent wastewater. The $\mathrm{p}$ values for turbidity and TP were 0.01 and 0.028 respectively indicating that they are both significant in predicting COD concentrations, with turbidity being highly significant due to its value being equal to the 0.01 boundary. M3 adopted the influent concentration of Tur, TP and PO4-P as the predictor variables. This model gave an adjusted $\mathrm{R}^{2}$ of 0.589 which indicates that the model is not overly reliable. The $\mathrm{F}$ value was found to be $2.13 \times 10^{-6}$ and this means that there is a statistical association as the null hypothesis can be rejected. The $\mathrm{p}$ value for $\mathrm{PO}_{4} \mathrm{P}$ was not enough to reject the null hypothesis that there is no significant statistical relationship, and so it can be said that it does not influence COD removal. The values for turbidity and TP, however, both reject the null hypothesis and so are considered significant.

M4 was constructed using the influent data for turbidity, $\mathrm{pH}$ and temperature as predictor variables. Relative to the other models, this model was found not to perform very well and this means that the model is not utile. The adjusted $\mathrm{R}^{2}$ value was only 0.446 . However the significant $\mathrm{F}$ value is less than 0.001 while Turbidity shows again that it is extremely significant in predicting the COD effluent concentrations as its $\mathrm{p}$ value is found to be less than 0.001. M6 was constructed using data obtained in real time only i.e. the influent $\mathrm{pH}$, ORP and temperature. This resulted in an adjusted $\mathrm{R}^{2}$ value of 0.588 . The $\mathrm{F}$ test resulted in the null hypothesis being rejected as the $\mathrm{F}$ value was lower than 0.001 , the threshold value being 0.05 . This indicates that there is indeed an important relationship to be observed. Analysis of the $\mathrm{p}$ values show temperature to be extremely significant as the value is below 0.001. The ORP value is technically not considered significant as its value of 0.052 implies that the null hypothesis can be rejected at a confidence level of $94.8 \%$. As this is only $0.2 \%$ below the level set during regression, it is safe to say that it has an important role in the prediction of COD effluents. These results are confirmed when the predicted effluent concentration is plotted against the observed COD in the effluent as shown in Fig. 2b. M6 proves to be a very useful model due to the fact that COD is an expensive parameter to measure, and now there is possibility that it can be estimated quite well using instantaneous results obtained in real time. It would be interesting to see the results for this model over a longer period of time to get a better description of the model. Selected plots of actual vs. 
predicted values for final effluent COD concentrations for models M2, M3 and M6, as presented in Figure 2b, generally indicate a good fit.

\subsubsection{Prediction of final effluent concentrations for soluble chemical oxygen demand}

Only one model, M3 was found to be of moderate suitability in predicting the sCOD concentration of the effluent (see Table 3 and Figure 2c). The model employed the influent concentrations of turbidity, SS and temperature as the predictor variables. This produced an adjusted $R^{2}$ value of 0.317 . The significant $F$ value of 0.001 was enough to reject the null hypothesis and say with $99.9 \%$ confidence that a statistical relationship is to be observed. When the $\mathrm{p}$ values of the predictor variables are considered, it can be seen that the only variable to be declared significant is that of turbidity with a value of 0.008 which is enough to imply that turbidity is highly important in predicting SCOD concentrations. Figure $2 \mathrm{c}$ shows the relationship between the actual and predicted values for the final effluent sCOD concentrations for models M2, M3 and M6 and they can all be considered relatively weak.

\subsubsection{Prediction of final effluent concentrations for total phosphorus}

For TP, three models (M1, M4 and M6) were adjudged to be best suited in predicting the effluent TP concentrations (see Table 3 and Figure 2d). M1 was constructed using the influent concentrations of turbidity, TN and $\mathrm{PO}_{4}-\mathrm{P}$ and it gave an adjusted $\mathrm{R}^{2}$ value of 0.591 . The significant $\mathrm{F}$ value was found to be $7.32 \times 10^{-6}$ and therefore it is said that there is a significant statistical association to be observed. From the analysis of the $\mathrm{p}$ values, the two variables that are considered to be significant in predicting TP concentrations in the effluent are TN, which is described as highly significant due to its value of 0.006 being between the limits of 0.01 and 0.001 ; and $\mathrm{PO}_{4}-\mathrm{P}$ which is considered to be significant due to its p value of 0.013 , which is lower than the 0.05 threshold, but very close to the margin of highly significant. M4 used the influent $\mathrm{NH}_{4}-\mathrm{N}, \mathrm{PO}_{4}-\mathrm{P}$ and $\mathrm{TN}$ as the predictor variables and this resulted in the adjusted $R^{2}$ value of 0.567 . The significant $F$ value retrieved from the $F$ test proves that there is a statistical relationship to be observed as its value is lower than the threshold value of 0.05 . When the $\mathrm{p}$ values are analysed, it can be seen that only $\mathrm{PO}_{4}-\mathrm{P}$ has a significant impact on the TP concentrations. This parameter, as expected, is considered significant due to it $\mathrm{p}$ value being between the limits of 0.05 and 0.01 . M6 used only data obtained in real time i.e. the influent $\mathrm{pH}$, ORP and temperature as the predictor variables and 
this resulted in the adjusted $\mathrm{R}^{2}$ value of 0.395 . The $\mathrm{F}$ test produced a significant $\mathrm{F}$ value of 0.029 and the null hypothesis can therefore be rejected as the value is lower than the 0.05 threshold, implying that there is a definite statistical relationship to be observed. Figure $2 \mathrm{~d}$ shows the plot of actual vs. predicted values for final effluent concentration for TP using models M1, M4 and M6. In general, the fit can be described as moderate, however, it is anticipated that the models can perform better if more data points over a long-term stable operation are employed.

\section{Impacts, implications and limitations of the study}

Results have demonstrated the efficiency of a two-stage alum sludge-based CW system in removing pollutants from wastewater. One of the wider benefits of the study could be in its application by farmers to reduce the pollution load of wastewater emanating from their practice. On the other hand, the study also has an impact on drinking water treatment plants that are constantly faced with the quagmire of disposing residual sludge from the treatment processes in a cost-effective and sustainable way. However, caution is urged before the largescale adoption of the novel CW system: (i) Occurrence of clogging is a possibility in the long-term and this is typical and inevitable in most CW systems. Several operational strategies including periodical bed resting can be used to delay and prolong the clogging time. In the current field CW system, signs of clogging were experienced after about a year of operation and the system was rested while further monitoring and evaluation are on-going; (ii) Being that the alum sludge is mainly composed of aluminium, there would be concerns as regards the leaching out of the aluminium into the effluent from the $\mathrm{CW}$ system. A separate field-scale investigation conducted in relation to this issue showed that aluminium was detected in the effluents from the CW system. However, except for the first three weeks of operation, the level of aluminium in the effluent from the $\mathrm{CW}$ system studied remained below the recommended limits of $0.2 \mathrm{mg} / \mathrm{l}$ for discharge throughout the remainder of the 42 -weeks monitoring period; (iii) Although the alum can serve to enhance $\mathrm{P}$ removal in such $\mathrm{CW}$ systems, it will eventually be saturated. However, Zhao et al. (2009) has shown that by using alum sludge in such systems, the lifetime of the system is extended significantly. In addition, Zhao and Zhao (2009a,b) carried out an investigation and showed that $\mathrm{P}$ can be recovered from the saturated alum sludge using a two-step process. Another option is the use of the saturated alum sludge as a slow P release fertilizer; (iv) An approach that identifies mathematical relationship between expensive/time consuming and inexpensive/quick water 
quality monitoring variables is also demonstrated in this study and this is essential for cost effective characterization of controlling processes within $\mathrm{CW}$ systems. However, such approach should include the analysis of the likelihoods of correct predictions if the final effluent concentrations are either below or above recommended thresholds.

\section{Conclusions}

1. Concurrent high removal rate of COD, ammonia, and phosphorous can be obtained in a two-stage constructed wetland system, demonstrating its potential use for cost-effective reduction of pollution load of agricultural wastewaters.

2. Model developed for predicting effluent biochemical oxygen demand and chemical oxygen demand given as $B O D 5=54.66 p H-0.03 O R P+8.29$ Temp -464.31 and $C O D=49.25 p H$ -0.34 ORP -39.36 Temp +314.39 respectively, proved strong. This can enable data obtained in real-time to be incorporated into computer programs to give more frequent BOD5 and COD readings.

3. Statistical modelling can be used to asses constructed wetland system performance and also to predict composition of the final effluent.

\section{Acknowledgments}

Authors wish to acknowledge financial support received for this field study from: (1) Enterprise Ireland under the Proof of Concept Scheme (project No. PC/2007/0308); (2) the Irish state Department of Agriculture, Fisheries and Food under the Research Stimulus Fund (project No. RSF 07-528). The UCD farms, Lyons Estate, Newcastle, Co. Dublin, Dr Edward Jordan and Mr Michael Hegarthy are all sincerely thanked for their support for the field work.

\section{References}


Akratos, C.S., Papaspyros, J.N., Tsihrintzis, V.A., 2009. Total nitrogen and ammonia removal prediction in horizontal subsurface flow constructed wetlands: Use of artificial neural networks and development of a design equation. Bioresour. Technol. 100, 586-596.

Albuquerque, A., Oliveira, J., Semitela, S., Amaral, L., 2009. Influence of bed media characteristics on ammonia and nitrate removal in shallow horizontal subsurface flow constructed wetlands. Bioresour. Technol. 100, 6269--6277.

Babatunde, A.O., Zhao, Y.Q., 2007. Constructive approaches towards water treatment works sludge management: An international review of beneficial re-uses. Crit. Rev. Environ. Sci. Technol. 37, $129-164$

Babatunde, A.O., Zhao, Y.Q., Burke, A.M., Morris, M.A., Hanrahan, J.P., 2009. Characterization of aluminium-based water treatment residual for potential phosphorus removal in engineered wetlands. Environ. Pollut. 157, 2830-2836.

Clesceri, L.S., Greenberg, A.E., Eaton, A.D., 1998. Standard Methods for the Examination of Water and Wastewater, 20th Ed. American Public Works Association, Washington, DC.

Gernaey, K.V., Van Loosdrecht, M.C.M., Henze, M., Lind, M., Jorgensen, S.B., 2004. Activated sludge wastewater treatment plant modelling and simulation: State of the Art. Environ. Model. Softwear, 19, 763-783.

Green, M., Friedler, E., Safrai, I., 1998. Enhancing nitrification in vertical flow constructed wetland utilizing a passive air pump. Water Res. 32, 3513-3520.

Kantawanichkul, S., Kladprasert, S., Brix, H., 2009. Treatment of high-strength wastewater in tropical vertical flow constructed wetlands planted with Typha angustifolia and Cyperus involucratus. Ecol. Eng. 35, 238-247.

Konnerup, D., Koottatep, T., Brix, H., 2009. Treatment of domestic wastewater in tropical, subsurface flow constructed wetlands planted with Canna and Heliconia. Ecol. Eng. 35, 248-257

Langergraber, G., 2008. Modeling of Processes in Subsurface Flow Constructed Wetlands: A Review. Vadoze Zone, 7, 830-842

Langergraber, G., Leroch, K., Pressl, A., Sleytr, K., Rohrhofer, R., Haberl, R., 2009. Highratenitrogen removal in a two-stage subsurface vertical flow constructed wetland. Desalination, 246, 55-68.

Lee, B-H., Scholz, M., 2006. A comparative study: Prediction of constructed treatment wetland performance with K-nearest neighbors and neural networks. Water, Air and Soil Pollut. 174, 279301.

Lin, Y.F., Jing, S-R., Lee, D-Y., 2002. Nutrient removal from aquaculture wastewater using a constructed wetlands system. Aquaculture, 209, 169-184.

Murray-Gulde, C.L., Bridges, W.C., Rodgers, J.H., 2008. Evaluating performance of a constructed wetland treatment system designed to decrease bioavailable copper in a waste stream. Environ. Geosci. 15, 21-38. 
Park, W.H., 2009. Integrated constructed wetland systems employing alum sludge and oyster shells as filter media for P removal. Ecol. Eng. 35, 1275-1282.

Tang, X., Eke, P.E., Scholz, M., Huang, S., 2009. Processes impacting on benzene removal in vertical-flow constructed wetlands. Bioresour. Technol. 100, 227-234.

Tao, W. and Wang, J., 2008. Effects of vegetation, limestone and aeration on nitratation, anammox and denitrification in wetland treatment systems. Ecol. Eng. 35, 836-842.

Tomenko, V., Sirajuddin, A., Viktor, P., 2007. Modelling constructed wetland treatment system performance. Ecol. Model. 205, 355-364.

Vymazal, J., 2007. Removal of nutrients in various types of constructed wetlands. Sci. Total Environ. $380,48-65$.

Wood, J., Fernandez, G., Barker, A., Gregory, J., Cumby, T., 2007. Efficiency of reed beds in treating dairy wastewater. Biosys. Eng. 98, 455-469.

Yang, Y., Zhao, Y.Q., Babatunde, A.O., Wang, L., Ren, Y.X., Han, Y., 2006. Characteristics and mechanisms of phosphate adsorption on dewatered alum sludge. Sep. Purif. Technol. 51, 193200.

Zhao, X.H., Zhao, Y.Q., 2009a. Investigation of phosphorus desorption from P-saturated alum sludge used as a substrate in constructed wetland. Sep. Purif. Technol. 66, 71-75.

Zhao, X.H., Zhao, Y.Q., 2009b. Decolouration of $\mathrm{H}_{2} \mathrm{SO}_{4}$ leachate from phosphorus-saturated alum sludge using $\mathrm{H}_{2} \mathrm{O}_{2}$ and advanced oxidation processes in phosphorus recovery strategy. J. Environ. Sci. Health, Part A: Toxic/Hazard. Subst. Environ. Eng. 44, 1557-1564.

Zhao, Y.Q., Zhao, X.H., Babatunde, A.O., 2009. Use of dewatered alum sludge as main substrate in treatment reed bed receiving agricultural wastewater: Long-term trial. Bioresour. Technol. 100, 644-648.

Zhao, Y.Q., Babatunde, A.O., Hu, Y.S., Kumar, J.L.G., Zhao, X.H., 2010. A two-prong approach of beneficial reuse of alum sludge in engineered wetlands: First experience from Ireland. Waste and Biomass Valorization, 1, 227-234. 



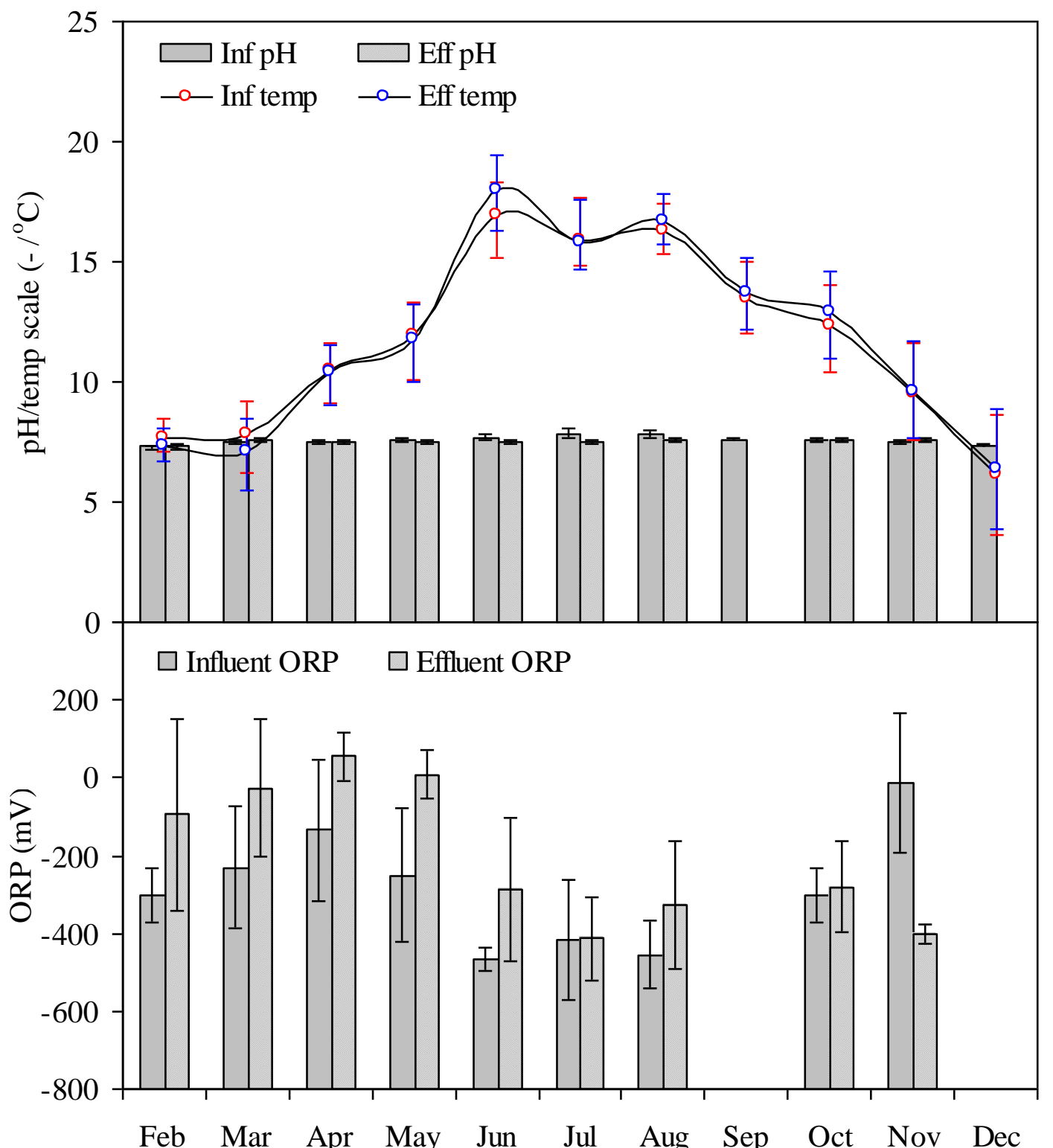



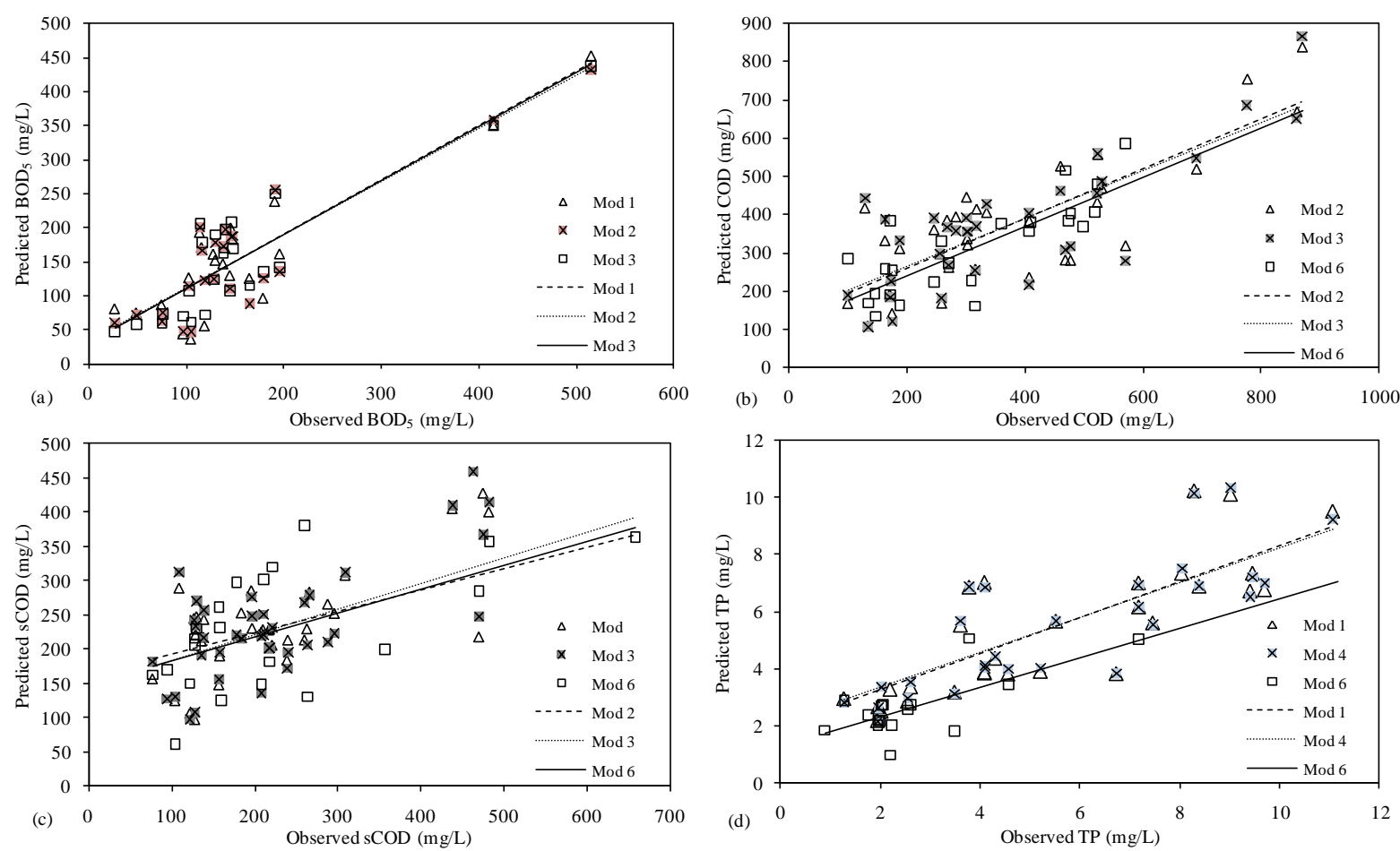
Table 1 Pollutant's loading and removal rates in the constructed wetland system

\begin{tabular}{c|c|ccccccccccc}
\hline \multirow{2}{*}{ Parameter } & $\begin{array}{c}\text { Rate } \\
\left(\mathrm{g} / \mathrm{m}^{2} . \mathrm{d}\right)\end{array}$ & Feb & Mar & Apr & May & Jun & Jul & Aug & Sep & Oct & Nov & Dec \\
\hline \multirow{2}{*}{ BOD $_{5}$} & Loading & nd & 13.2 & 19.0 & 17.8 & 212.8 & 134.2 & 178.2 & 132.9 & 229.9 & 363.3 & 230.4 \\
& Removal & nd & 9.0 & 9.5 & 4.6 & 103.0 & 67.9 & 105.3 & 56.6 & 104.2 & 249.2 & 175.3 \\
\hline \multirow{2}{*}{$\mathrm{COD}$} & Loading & nd & 202.3 & 161.6 & 145.2 & 298.4 & 212.1 & 365.6 & 387.0 & 550.4 & 726.6 & 390.6 \\
& Removal & nd & 43.1 & 63.6 & 35.6 & 126.0 & 105.2 & 200.9 & 232.1 & 226.9 & 502.0 & 327.3 \\
\hline \multirow{2}{*}{$\mathrm{SCOD}$} & Loading & nd & 199.8 & 72.6 & 65.6 & 173.4 & 126.9 & 211.2 & 231.5 & 392.4 & 587.3 & 282.8 \\
& Removal & nd & 50.2 & 27.0 & 7.5 & 65.7 & 48.3 & 98.5 & 130.1 & 206.4 & 459.9 & 221.8 \\
\hline \multirow{2}{*}{$\mathrm{SS}$} & Loading & 101.6 & 79.7 & 50.2 & 41.7 & 65.2 & 65.5 & 81.2 & 95.8 & 128.9 & 194.1 & 151.2 \\
& Removal & 48.3 & 39.3 & 25.2 & 16.4 & 30.9 & 32.8 & 34.1 & 63.6 & 64.0 & 113.3 & 106.7 \\
\hline \multirow{2}{*}{$\mathrm{PO}_{4}-\mathrm{P}$} & Loading & 8.2 & 4.3 & 3.1 & 6.5 & 9.2 & 7.4 & 13.3 & 15.0 & 18.4 & 15.3 & 10.1 \\
& Removal & 6.9 & 3.6 & 2.7 & 5.3 & 7.7 & 4.7 & 9.4 & 12.9 & 14.6 & 11.9 \\
\hline \multirow{2}{*}{$\mathrm{TN}$} & Loading & 26.9 & 22.6 & 28.0 & 13.8 & 61.0 & 47.7 & 112.6 & 121.5 & 114.4 & 73.9 & 60.6 \\
& Removal & 1.3 & 2.1 & 15.0 & 5.8 & 27.6 & 24.8 & 32.2 & 34.3 & 37.9 & 52.7 & 42.7 \\
\hline \multirow{2}{*}{$\mathrm{NH}_{4}-\mathrm{N}$} & Loading & 23.6 & 20.5 & 12.1 & 15.8 & 39.0 & 34.0 & 71.9 & 90.9 & 98.7 & 61.1 & 51.2 \\
& Removal & 14.0 & 6.1 & 6.5 & 12.6 & 18.2 & 17.3 & 24.6 & 61.3 & 53.3 & 44.7 & 37.7 \\
\hline
\end{tabular}

nd- not determined 
Table 2 Correlation matrix for effluent concentrations (top) and influent and effluent concentrations (below)

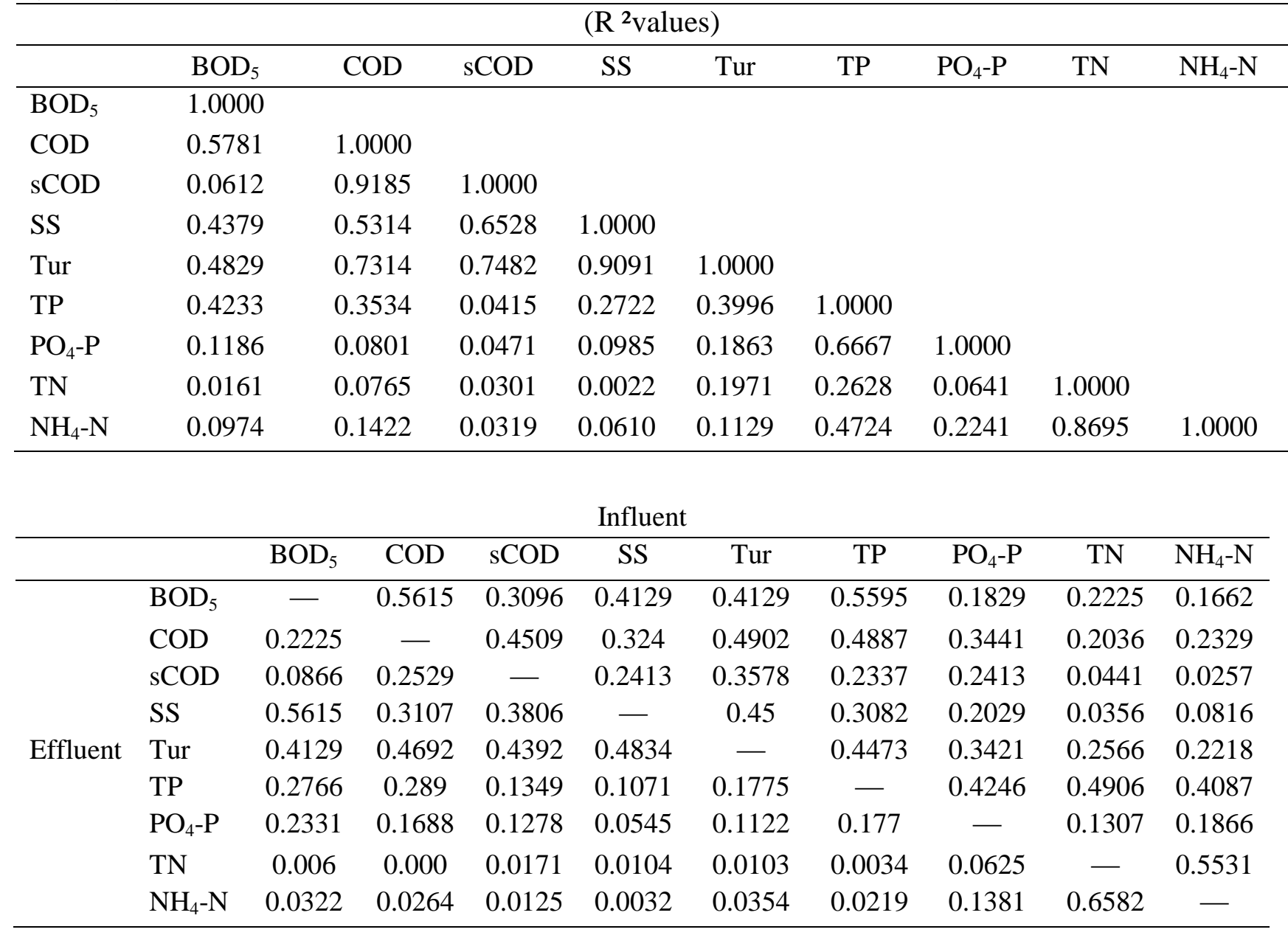


Table 3 Predictive models and evaluation of fit

\begin{tabular}{|c|c|c|c|c|c|c|c|}
\hline \multirow[t]{2}{*}{ Dependant Variables } & \multirow{2}{*}{$\begin{array}{r}\text { Model } \\
\text { M1 }\end{array}$} & \multicolumn{3}{|c|}{ Predictor influent Variables } & \multirow{2}{*}{$\begin{array}{r}\text { Constant } \\
+0.310\end{array}$} & \multirow{2}{*}{$\begin{array}{r}\text { Sig F } \\
8.52 \times 10^{-7}\end{array}$} & \multirow{2}{*}{$\begin{array}{r}\frac{\mathrm{R}^{2}}{0.765} \\
0.7\end{array}$} \\
\hline & & $-0.007(\mathrm{SS})$ & $+3.072(\mathrm{TP})$ & +1.341 (Tur)*** & & & \\
\hline \multirow{5}{*}{ BOD } & M2 & $66.670(\mathrm{pH})$ & $+0.104(\mathrm{SS})$ & +1.354 (Tur) $* *$ & -530.731 & $1.60 \times 10^{-6}$ & 0.749 \\
\hline & M3 & 7.542(Temp) & $+0.144(\mathrm{SS})^{*}$ & +1.167 (Tur) ${ }^{* *}$ & -133.708 & $9.18 \times 10^{-7}$ & 0.763 \\
\hline & M4 & $2.45 \times 10^{-4}\left(\mathrm{PO}_{4}-\mathrm{P}\right)$ & +0.069 (SS) & +1.478 (Tur) ${ }^{* * *}$ & -1.658 & $3.44 \times 10^{-6}$ & 0.727 \\
\hline & M5 & $9.094(\mathrm{pH})$ & $+14.073(\text { Temp) })^{* *}$ & $+0.767(\mathrm{SS}) * * *$ & -274.018 & $3.73 \times 10^{-6}$ & 0.612 \\
\hline & M6 & $54.662(\mathrm{pH})$ & $-0.032(\mathrm{ORP})$ & $+8.287(\mathrm{Temp})$ & -464.307 & 0.001 & 0.665 \\
\hline \multirow{6}{*}{ COD } & M1 & 1.563 (Tur) & +0.809 (Temp) & $+0.273(\mathrm{SS})$ & +100.462 & $3.57 \times 10^{-4}$ & 0.325 \\
\hline & M2 & 1.333 (Tur)** & $+19.566(\mathrm{TP})^{*}$ & $+0.126(\mathrm{sCOD})$ & +27.690 & $8.44 \times 10^{-7}$ & 0.615 \\
\hline & M3 & 1.741 (Tur)*** & $+20.659(\mathrm{TP})$ & $+0.454\left(\mathrm{PO}_{4}-\mathrm{P}\right)$ & +28.343 & $2.13 \times 10^{-6}$ & 0.589 \\
\hline & M4 & 2.085 (Tur)*** & $-62.817(\mathrm{pH})$ & +2.538 (Temp) & +567.995 & $4.82 \times 10^{-6}$ & 0.446 \\
\hline & M5 & $-48.669(\mathrm{pH})$ & +0.021 (Temp) & $+0.846(\mathrm{SS}) * * *$ & +564.254 & 0.002 & 0.251 \\
\hline & M6 & $49.250(\mathrm{pH})$ & $-0.343(\mathrm{ORP})$ & $-39.357(\text { Temp) })^{* * *}$ & +314.393 & $1.07 \times 10^{-4}$ & 0.588 \\
\hline \multirow{6}{*}{ sCOD } & M1 & 1.049(Tur) & $+0.017(\mathrm{SS})$ & $+1.414(\mathrm{TP})$ & +66.924 & 0.012 & 0.231 \\
\hline & M2 & 1.011(Tur) & $+0.041(\mathrm{SS})$ & $+1.852\left(\mathrm{PO}_{4}-\mathrm{P}\right)$ & +54.308 & 0.01 & 0.242 \\
\hline & M3 & $1.045(\mathrm{Tur})^{* *}$ & $+0.069(\mathrm{SS})$ & -3.483 (Temp) & +126.657 & 0.001 & 0.317 \\
\hline & M4 & $0.497(\mathrm{SS}) *$ & $-0.041(\mathrm{TP})$ & -3.383 (Temp) & +163.797 & 0.02 & 0.191 \\
\hline & M5 & $0.323(\mathrm{SS})$ & +0.140 (Tur) & $+0.299(\mathrm{TN})$ & +109.345 & 0.204 & 0.06 \\
\hline & M6 & $-7.761(\mathrm{pH})$ & $-0.407(\mathrm{ORP})$ & -30.132 (Temp) & $\begin{array}{r}+545.709 \\
\end{array}$ & 0.058 & 0.233 \\
\hline \multirow{6}{*}{ TP } & M1 & -0.003 (Tur) & $+0.018(\mathrm{TN})^{* *}$ & $+0.116\left(\mathrm{PO}_{4}-\mathrm{P}\right)^{*}$ & +0.395 & $7.32 \times 10^{-6}$ & 0.591 \\
\hline & M2 & $0.013(\mathrm{TN})$ & +0.008 (Tur) & $+0.005(\mathrm{SS})$ & +0.171 & 0.002 & 0.387 \\
\hline & M3 & 0.009 (SS) & +0.008 (Tur) & +0.269 (Temp) & -1.549 & 0.037 & 0.172 \\
\hline & M4 & $-0.001\left(\mathrm{NH}_{4}-\mathrm{N}\right)$ & $+0.104\left(\mathrm{PO}_{4}-\mathrm{P}\right)^{*}$ & $+0.018(\mathrm{TN})$ & +0.333 & $2.29 \times 10^{-5}$ & 0.567 \\
\hline & M5 & $0.006(\mathrm{SS})$ & +0.011 (Tur) & $+2.956(\mathrm{pH})$ & -20.338 & 0.103 & 0.102 \\
\hline & M6 & $11.213(\mathrm{pH})^{*}$ & +0.001(ORP) & -0.318 (Temp) & -78.671 & 0.029 & 0.395 \\
\hline
\end{tabular}

$\mathrm{P}<0.05=*$ =significant, $\mathrm{P}<0.01=* *=$ Highly significant, $\mathrm{P}<0.001=* * *$ Extremely significant 